\title{
Drying-induced physico-chemical changes in cranberry products
}

${ }^{1}$ Institute of Animal Reproduction and Food Research of the Polish Academy of Sciences, Division of Food Science, Tuwima 10, 10-748 Olsztyn, Poland

${ }^{2}$ Wrocław University of Environmental and Life Sciences, Faculty of Food Science, Department of Fruit, Vegetable and Plant Nutraceutical Technology, Chełmońskiego 37, 51-630 Wrocław, Poland

${ }^{3}$ University of Applied Sciences and Arts Western Switzerland Valais (HES-SO Valais-Wallis), Institute of Life Technologies, Route du Rawyl 47, 1951 Sion, Switzerland

corresponding author: Anna Michalska, Ph.D.

Institute of Animal Reproduction and Food Research of the Polish Academy of Sciences, Division of Food Science, Tuwima 10, 10-748 Olsztyn, Poland; tel.: +48 89 5234641, e-mail: a.michalska@pan.olsztyn.pl 


\section{Abstract}

Sugar-free cranberry juice (XAD) and juice with $15 \%$ of maltodextrin were dried by freeze-, vacuum and spray drying methods. Total phenolics (589- $6435 \mathrm{mg} / \mathrm{kg}$ dry matter) including 5 flavonols, 3 phenolic acids, 2 procyanidins and 5 anthocyanins were stronger affected by juice formulation than by drying methods. Spray drying of juice, regardless of its formulation, was competitive to freeze drying in terms of polyphenols' retention. Increase in temperature up to $100{ }^{\circ} \mathrm{C}$ during vacuum drying of XAD extracts resulted in degradation of polyphenolics (down to $4 \%$ ), except chlorogenic acid. Its content increased with rise in temperature and accelerated hydroxymethylfurfural formation. The stronger the impact of drying, the more chlorogenic acid is present in cranberry products. In all powders analysed, formation of furoylmethyl amino acids was noted. Antioxidant capacity of cranberry products was influenced by juice formulation and was linked to content of polyphenols.

\section{Keywords}

Vaccinium ssp., powders, drying, polyphenols, hydroxymethylfurfural, furoylmethyl amino acids

\section{Highlights}

- Formulation of cranberry juice strongly affected the content of polyphenols.

- Formation of hydroxymethylfurfural was accelerated by chlorogenic acid.

- 2-furoylmethyl-amino acids were present in all cranberry juice powders.

- Antioxidant capacity was dependent on polyphenols content. 


\section{Introduction}

Cranberry (Vaccinium ssp. L.) is an evergreen dwarf shrub that produce edible red fruits, which are rich in vitamins (A, C, B1, B2, B6 and E), minerals, sugars, organic acids and fibre (Borges, Degeneve, Mullen, \& Crozier, 2010). Furthermore, this fruit contains significant amounts of phenolic compounds including procyanidins (PACs), phenolic acids, anthocyanins, flavonols and flavan-3-ols with strong antioxidant properties (Sun, Chu, Wu, \& Liu, 2002; Borowska, Mazur, Gadzala-Kapciuch, \& Buszewski, 2009). Due to the presence of those biologically active constituents cranberries could prevent from i.e. urinary tract infections, reduce the risk of cardiovascular diseases and selected types of cancer, and might have antifungal, antimicrobial, antianemic and detoxifying properties (Blumberg et al., 2013). Taking into account the various beneficial effects of cranberries on human health, consumption of these fruits is recommended. However, the bitter and astringent taste hampers its consumption in a fresh form. Therefore, technological transformations of cranberries are necessary to decrease the inacceptable taste. Taking into consideration that fruit processing results in significant changes in the profile and the content of biologically active constituents (Nicoli, Anese, \& Parpinel, 1999; Horszwald, Andlauer, \& Heritier, 2013; Michalska, Wojdyło, Lech, Łysiak, \& Figiel, 2016), the processing of the cranberries should be done in a way to get consumer acceptance with a minimum loss of beneficial compounds. Previous studies showed that juicing (White, Howard, \& Prior, 2011; Côté et al., 2011; Caillet, Côté, Doyon, Sylvain, \& Lacroix, 2011), freeze- (Vvedenskaya et al., 2004) and vacuum microwave drying (Leusink, Kitts, Yaghmaee, \& Durance, 2010) of cranberries have strong effects on polyphenolic compounds content and the antioxidant capacity. There is a strong link between processing parameters and alteration in phytochemicals profile and quantity in the products. Interestingly, evaluation of cranberries juice concentrates and freeze-dried powders revealed that some flavonol aglycons were present in the final products only after processing. From this point of view, the production of cranberry juice powders might be a practical tool to prolong the cranberry availability on the market throughout the year and to provide promising bioactive compounds.

The preparation of fruit juices before drying is a key factor for obtaining fine powders, independent from the drying methods applied (Caparino et al., 2012)(Fegus, Zigon, Peterman, \& Zeljko, 2015)(Oberoi \& Sogi, 2015). Fruit juices cannot be directly converted to a powder form because of the presence of low molecular weight acids and carbohydrates with a low glass transition temperature (Bhandari, Senoussi, Dumoulin, \& Lebert, 1993) and stickiness behaviour. These issues might be overcome by adding a carrier agent i.e. maltodextrin before drying that could affect physicochemical properties of the final powders (Oberoi \& Sogi, 2015). When preparing the fruit powders, another aspect that should be considered is the formation of the compounds via Maillard reaction/caramelisation (Michalska, Wojdyło, et al., 2016). Newlyformed constituents after fruit drying were confirmed in pears (Coimbra, Nunes, Cunha, \& Guiné, 2011), plum products (Michalska, Honke, Łysiak, \& Andlauer, 2016; Michalska, Wojdyło, Lech, Łysiak, \& Figiel, 2016), prunes, dried figs (Sanz, del Castillo, Corzo, \& Olano, 2001) and selected berries (Megías-Pérez, Gamboa-Santos, Soria, Villamiel, \& Montilla, 2014). Thus, Maillard reaction products might serve as a quality indicator for the dry powders. Up to now, powders from cranberry whole fruits, pomace and juice obtained after freeze-drying (Vvedenskaya et al., 2004; Oszmiański, Wojdyło, Lachowicz, Gorzelany, \& Matłok, 2016) were analysed for their polyphenolic compounds content. However, no data for cranberry juice formulation and other drying techniques than freeze-drying are available.

Thus, the aim of the study was to evaluate the influence of the cranberry juice formulation and the effect of different drying methods (freeze-drying, vacuum drying and spray drying) on the profile and quantity of polyphenols, Maillard reaction/caramelisation products and the antioxidant capacity of the powders obtained.

\section{Materials and methods}




\subsection{Reagents}

Maltodextrin, hydroxymethylfurfural, Trolox ${ }^{\circledR}, 2,2^{\prime}$-azino-bis(3-ethylbenzothiazoline-6-sulfonic acid) diammonium salt, potassium persulfate, 2,2-diphenyl-1-picrylhydrazyl (DPPH) were purchased from Sigma-Aldrich (Switzerland). Cyanidin-3-O-glucoside, peonidin-3-O-glucoside quercetin-3-O-glucoside and quercetin-3-O-rutinoside were obtained from Extrasynthese (Lyon, France). Chlorogenic acid was obtained from TRANS MIT GmbH (Giessen, Germany). Furosine was purchased from PolyPeptide Group (Strasbourg, France). Acetonitrile for UPLC (Gradient Grade) was from Merck (Darmstadt, Germany). Water for UPLC analysis was prepared using the HLP SMART 1000s system (Hydrolab, Gdansk, Poland) was additionally filtrated through a $0.22 \mu \mathrm{m}$ membrane filter. The amberlite XAD-16 resin was supplied by Brenntag (Kędzierzyn-Koźle, Poland).

\subsection{Material}

Five litres of a commercial cranberry juice $\left(100 \%\right.$, pasteurised; Rabenhorst ${ }^{\circledR}$, Unkel/Rhain, Germany; $8{ }^{\circ} \mathrm{Br}, \mathrm{pH} 2.53 \pm 0.1$ ) were centrifuged for $15 \mathrm{~min}$ at $5950 \mathrm{~g}$ (HiCen XL, Herolab, $\mathrm{GmbH}$ Laborgeraete, Germany). Supernatant obtained was divided into two parts. One part was loaded into a vacuum aspirated column with amberlite XAD-16 resin previously conditioned with water (Kammerer et al., 2005; Seeram et al., 2005). The absorbed compounds were eluted with ethanol that was removed by scale rotary evaporator Laborota 20 (Heidolph, Schwabach, Germany) at $40^{\circ} \mathrm{C}$ down to the final volume of $2 \mathrm{~L}$ giving the sugar-free cranberry juice extract (XAD). The second part of the centrifuged juice (supernatant) was mixed with $15 \%(\mathrm{v} / \mathrm{w})$ of commercial maltodextrin (dextrose equivalent: 19$)(15 \% \mathrm{M})$. Both formulations of the juice (XAD and juice containing $15 \%$ of maltodextrin) were subjected to the drying processes.

\subsection{Methods}

\subsubsection{Drying processes}

The two cranberry formulations (XAD and $15 \% \mathrm{M})(250 \mathrm{~mL}$ each, $n=3)$ were subjected to: freeze-drying (FD; LSL Secfroid, Lyolab BII, Aclens-Lausanne, Switzerland) at $0.03 \mathrm{mbar}$; vacuum drying (VD; Vacuum drying oven, Salvis Lab, Rotkreuz, Switzerland) at $200 \mathrm{mbar}$ at $40^{\circ} \mathrm{C}, 60^{\circ} \mathrm{C}, 80^{\circ} \mathrm{C}$ and $100^{\circ} \mathrm{C}$ and spray drying (SD; Mini spray dryer, B-290, Büchi Labor Technik AG, Flawil, Switzerland) at $50 \%$ of pump capacity, aspirator at $100 \%$ represented an air flow from $35 \mathrm{~m}^{3} / \mathrm{h}$ (Table 1). Powders obtained were pulverised by a mill (Bosch, MKM 6003, Gerlingen, Germany) using a sieve of $1.0 \mathrm{~mm}$ diameter (Retsch SM-100, Hann, Germany), vacuum packed and stored at $-20^{\circ} \mathrm{C}$ until analyses.

\subsubsection{Water content}

Water content in cranberry powders was determined by Karl-Fisher method using $803 \mathrm{KF}$ Titration Stand (Metrohm, Herisau, Switzerland) in three independent measurements $(n=3)$ and expressed as percentage (\%) ( \pm SD). 
using the Acquity Ultraperformance LC system (Waters Corp., Milford, USA) coupled with a photodiode detector (PDA; UPLC) connected with a mass detector G2 (QTOf) Micro mass spectrometer (Waters, Manchester, UK) equipped with an electrospray ionization (ESI) source operating in negative mode. The UPLC BEH C ${ }_{18}$ column $(2.1 \times 50 \mathrm{~mm} ; 1.7 \mu \mathrm{m}$; Waters Corp., Milford, USA) set at $30^{\circ} \mathrm{C}$ was applied for polyphenols' separation (Wojdyło et al., 2013). The quantification of polyphenolic compounds in powders analysed was performed as described by Wojdyło et al. (2014). The runs were monitored at the wavelengths: phenolic acid at $320 \mathrm{~nm}$, flavonols at $360 \mathrm{~nm}$ and anthocyanins at $520 \mathrm{~nm}$. Retention times $\left(T_{R}\right)$ and spectra were compared with those of pure standards. Calibration curves $\left(0.05\right.$ to $\left.5 \mathrm{mg} / \mathrm{mL}, R^{2} \leq 0.9998\right)$ were made from chlorogenic acid, peonidin-3-O-glucoside, cyanidin-3-O-glucoside, quercetin-3-Oglucoside and -3-O-rutinoside as standards. All determinations were done in triplicates $(n=3)$ and the results were expressed as $\mathrm{mg} / \mathrm{kg}$ dry matter ( $\mathrm{dm}$ ).

\subsubsection{Antioxidant capacity}

The antioxidant capacity was measured by Trolox Equivalent Antioxidant Capacity tests against $\mathrm{ABTS}^{*}+$ (Re et al., 1999) and $\mathrm{DPPH}^{*}$ radicals (Brand-Williams et al., 1995) adjusted to microplate reader according to Horszwald \& Andlauer (2011). Cranberry powders (100 mg) were solubilised in $10 \mathrm{~mL}$ of deionised water and left for $24 \mathrm{~h}$. After this time, samples were sonicated ( $2 \times 3 \mathrm{~min}$, ambient temperature) and centrifuged (5 $000 \mathrm{rpm}, 5 \mathrm{~min}, 21^{\circ} \mathrm{C}$; Eppendorf 5415 R, Eppendorf AG, Hamburg, Germany). The results obtained from the two tests were expressed as mmol of Trolox Equivalents (TE)/100 g dm. Results given are average values $( \pm \mathrm{SD})$ of at least three independent extractions.

Photoluminescence (PCL) assay was applied for evaluation of the antioxidant capacity of the cranberry powders with the Photochem ${ }^{\circledR}$ apparatus (Analytik Jena, Leipzig, Germany). The antioxidant capacity of hydrophilic (ACW) and lipophilic (ACL) extracts was measured against superoxide anion radicals generated from a photosensitiser luminol exposed to UV light using both 'ACW' and 'ACL' kits provided by the manufacturer. Approx. $0.5 \mathrm{~g}$ of powder were extracted with $5 \mathrm{~mL}$ of deionised water (ACW) or $80 \%$ methanol (ACL) by sonication (2 min) and vortexing $(1 \mathrm{~min})$. The samples were centrifuged for $5 \mathrm{~min}\left(5000 \mathrm{~g}, 5 \mathrm{~min}, 4^{\circ} \mathrm{C}\right.$; Eppendorf 5415 R, Eppendorf AG, Hamburg, Germany). The step was repeated 3 times. Supernatants obtained were unified before analyses. The total extraction procedure was carried out in triplicate $(n=3)$, and the antioxidant capacity was expressed as mmol Trolox $/ 100 \mathrm{~g} \mathrm{dm}$.

\subsubsection{Determination of Maillard reaction/caramelisation products}

Determination of 2-furoylmethyl amino acids (2-FM-AA) was performed by modified method of Megias-Perez et al. (2014) described in details by Michalska et al. (2016). Quantitative analysis was performed by the external standard method using a commercial standard of pure furosine. Data were the average values $( \pm \mathrm{SD})$ of at least three independent hydrolysis $(n=3)$ expressed as $\mathrm{mg} / 100 \mathrm{~g} \mathrm{dm}$.

The content of hydroxymethylfurfural (HMF) was evaluated using the Acquity UPLC system (Waters Corp., Milford, USA) according to Gökmen \& Senyuva (2006). HMF was detected at $284 \mathrm{~nm}$ and quantified using a standard curve. The results were indicated as average values of 3 independent extractions $(n=3)$ and shown as $\mathrm{mg} \mathrm{HMF} / \mathrm{kg} \mathrm{dm} \mathrm{(} \pm$ SD).

\subsubsection{Colour}

The colour of the cranberry powders obtained using different drying techniques was examined with reference to the colour space CIE $L^{*} a^{*} b^{*}$ using a Minolta Chroma Meter CR-400 (Minolta Co. Ltd., Osaka, Japan). The colour coordinates of the samples were determined using Illuminant D65 and $2^{\circ}$ observer angle, and the samples were measured against a white ceramic reference plate $\left(L^{*}=93.8 ; a^{*}=31.6 ; b^{*}=33.2\right)$. Data were showed as an average value of five measurements $( \pm \mathrm{SD})$. 


\subsubsection{Statistical analysis}

Statistical analysis was done using Statistica 10 (Statistica, Tulsa, OK, USA). Average values were subjected to one-way analysis of variance (ANOVA) and least significance test HSD Tukey was used to compare the difference. Differences between averages were considered to be significant at $p<0.05$.

\section{Results and discussion}

\subsection{Identification and quantification of polyphenolic compounds}

In powders obtained from commercial cranberry juice, 15 polyphenolic compounds were identified by LC-MS (QTof): 5 flavonols, 3 phenolic acids, 2 flavanols and 5 anthocyanins (Table 2). The total content of phenolic compounds (TP) in the powder ranged from 590 to $6436 \mathrm{mg} / \mathrm{kg}$ $\mathrm{dm}$ (Table 3). Considerably variable amounts of TP in cranberries products were previously reported (Leusink et al., 2010; Caillet et al., 2011; Vvedenskaya et al., 2004) indicating the strong impact of processing on the stability of polyphenolic compounds in the final cranberry products. In the current study, the highest content of TP was obtained by spray- and freezedrying of sugar-free cranberry extract (XAD) that was approx. $8.5 \%, 30 \%, 56 \%$, and $64 \%$ higher when compared to powders obtained using VD, respectively, at $40{ }^{\circ} \mathrm{C}, 60^{\circ} \mathrm{C}, 80^{\circ} \mathrm{C}$ and 100 ${ }^{\circ} \mathrm{C}$. Spray drying of cranberry sugar free extracts (XAD) might be considered as competitive to freeze drying regarding preservation of polyphenols. The average TP content in $15 \% \mathrm{M}$ powders was 5 times lower when compared to the average value obtained for XAD powders indicating a strong influence of the juice formulation on powder quality. In this group of powders, the highest retention of TP was noted after FD, whereas their content was $16 \%$ lower when SD and VD at $40{ }^{\circ} \mathrm{C}$ were used. Increase in the temperature during VD resulted is a stronger degradation of TP being the highest (approx. $40 \%$ ) when a temperature of $100{ }^{\circ} \mathrm{C}$ was applied. Nevertheless, the decrease of TP content was lower in case of $15 \% \mathrm{M}$ juice in comparison to the XAD juice. The addition of maltodextrin seemed to protect the polyphenolic compounds from the temperature degradation as the TP at $40^{\circ} \mathrm{C}$ and $80^{\circ} \mathrm{C}$ were at the similar levels.

Similarly to previous studies, four major groups of polyphenolic compounds were assigned in cranberry powders (Vvedenskaya et al., 2004; White et al., 2011). The main group of polyphenols present in cranberry powders ( $62 \%$ of all polyphenols) consisted of 5 flavonols. The tentative identifications were made by comparing their PDA spectra. MS and MS/MS and the molecular ions $[\mathrm{M}-\mathrm{H}]^{-}$(Table 2) enabled the identification. This group of polyphenols consisted of five quercetin glycosides with the characteristic fragment ion at $\mathrm{m} / \mathrm{z} 301$ : 3-Ogalactoside ([M-H] at $\mathrm{m} / \mathrm{z}$ 463)(Côté, Caillet, Doyon, Sylvain, \& Lacroix, 2010)(Swaldi et al., 2012)(Oszmiański et al., 2016), 3-O-pentoside ([M-H] at $\mathrm{m} / \mathrm{z}$ 433)(Oszmiański et al., 2016), 3O-rhamnoside ([M-H] $]^{-}$at $\mathrm{m} / \mathrm{z}$ 447) (Oszmiański et al., 2016) and, benzoyl-galactoside ([M-H] at $\mathrm{m} / \mathrm{z}$ 567)(Côté et al., 2010; Swaldi et al., 2012; Oszmiański et al., 2016). Similar to fresh cranberries (Zheng \& Shetty, 2000) and spray dried cranberry products (Vvedenskaya et al., 2004), quercetin-3-O-galactose was the main flavonol analysed regardless of the juice formulation; however, Vvedenskaya et al. (2004) showed that the flavonol constituents were present in significant quantities only after processing.

Drying processes influenced the content of individual flavonols in cranberry powders, and this was strictly connected with the juice formulation. The highest and comparable quantity of flavonols in powders made from sugar free juice extract (XAD) was noted after FD and SD. SD might be successfully used in terms of comparable retention of flavonols in cranberry products and in terms of the costs limitation during powders production. The increasing temperature during VD resulted in a degradation of flavonols in powders obtained from sugar free extract (XAD) even down to $4 \%$ in case of quercetin-3-O-galactoside, quercetin-3-O-pentoside and quercetin-3-O-rhamnoside. The exception was the aglycon quercetin. And it was previously shown that in foods with high content of quercetin conjugates, a high temperature up to $100{ }^{\circ} \mathrm{C}$ 
might retain this constituent (Aherne \& O'Brien, 2002). Additionally, quercetin can be regenerated by the before mentioned glycosides. It was confirmed that heating of cranberry pomace resulted in an increase of flavonols aglycones as a result of the deglycosylation of flavonol glycosides (White et al., 2011). Similarly to this study, the highest content of quercetin was noted after drying at $60^{\circ} \mathrm{C}$ (White et al., 2011). Significantly lower content of flavonols in powders obtained from 15\% M juice. Among powders obtained in this group, the highest content of all individual flavonols was noted after FD. In VD of $15 \% \mathrm{M}$ juice, the quercetin content increased after drying at $60^{\circ} \mathrm{C}$ reaching the highest content at $80^{\circ} \mathrm{C}$. The second group of phenolic compounds present in cranberry powders ( $20 \%$ of all polyphenols) comprised of 3 constituents eluted between 4.21 and $4.53 \mathrm{~min}$ and classified as phenolic acids (Table 2). Peak identified at $T_{R} 4.21$ min corresponded to caffeoyl hexoside with a precursor ion at $\mathrm{m} / \mathrm{z}$ 341 and fragment ion at 179 . Peak at $T_{R} 4.33$ was ascribed as chlorogenic acid with $\mathrm{m} / \mathrm{z} 353$ and fragment ions at $\mathrm{m} / \mathrm{z} 191$ and 146 corresponded to quinic acid moiety as reported by Swaldi et al. (2012) and Côté et al. (2010). The third peak was ascribed as $p$-coumaroyl hexose isomer with $m / z 325$ and ion fragment at $m / z 163$. Peak assignments were in agreement with Wang \& Zuo (2011) and Diaz-Garcia et al. (2013).

Similarly to cranberry juice (Diaz-Garcia et al., 2013), among all phenolic acids present in the cranberry powders the highest content of $p$-coumaroyl hexose was noted followed by caffeoyl hexoside and chlorogenic acid. Juice formulation affected the content of phenolic acids in the powders (Table 3). Almost 5 times higher contents of phenolic acids were indicated in powders obtained from XAD drying when compared to $15 \%$ M juice drying. In case of XAD, FD and SD resulted in the highest retention of phenolic acids. Increase in the temperature during VD drastically decreased concentration of $p$-coumaroyl hexose isomer, even down to $2 \%$ when a temperature of $100^{\circ} \mathrm{C}$ was applied. Conversion of certain phenolic acids during the processing of cranberries has been previously stated. Chen, Zuo and Deng (2001) reported the presence of chlorogenic acid in cranberry juice, but not in fresh fruits indicating the influence of processing on the occurrence of this compound. In the current study, the higher the temperature during the VD of XAD, the higher the ratio in the content of caffeoyl-hexoside conjugate to chlorogenic acid. VD at $100{ }^{\circ} \mathrm{C}$ resulted in 2.3 times higher content of chlorogenic acid when compared to FD or SD. Addition of maltodextrin and different drying techniques applied affected the content of individual phenolic acids in cranberry products, but to a different extend than in case of sugar free juice (XAD). The content of dominant phenolic acid, $p$-coumaroyl-hexose was the greatest when SD was applied. Increase in the temperature during VD caused only a slight decrease in the content of $p$-coumaroyl-hexose. And also caffeoyl-hexoside and chlorogenic acid were protected by the addition of maltodextrin compared to XAD (Table 3).

The third group of eluted compounds belong to the flavanols ( $12 \%$ of all polyphenols) among which two A-type PA-dimers were identified ( $T_{R} 4.09$ and $4.66 \mathrm{~min}$ ) with $\mathrm{m} / \mathrm{z} 575$ and fragmentation ions at $\mathrm{m} / \mathrm{z} 289$ (Table 2). Literature shows that juicing process followed by pasteurisation significantly reduced the flavanols content which explains the low content of flavanols in the analysed cranberry powders (White et al., 2011). Similarly to previously described groups of polyphenolic compounds present in cranberry powders, the average content of flavanols was approx. 5.3 times higher in products gained after sugar free juice (XAD) drying when compared to $15 \% \mathrm{M}$ juice drying. In both cases, VD resulted in greatest degradation of flavonols in comparison to FD and SD (Table 3).

Anthocyanins ( $6 \%$ of all polyphenols) consisted of 5 compounds identified in cranberry powders by LC/MS technique (Table 2) (Díaz-García, Obón, Castellar, Collado, \& Alacid, 2013): two glycosides of cyanidin $\left([\mathrm{M}+\mathrm{H}]^{+}\right.$at $\mathrm{m} / \mathrm{z}$ 287.05): 3-O-galactoside and 3-O-

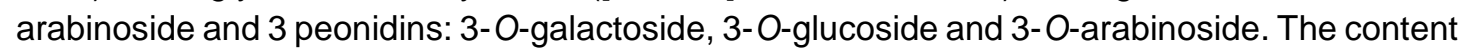
of anthocyanins in powders was relatively low as a strong negative impact on anthocyanins retention (2-30\%) during cranberry juicing has been noted (Pappas \& Schaich, 2009). As it was observed for fresh cranberry fruits (White et al., 2011) and juices (Díaz-García et al., 2013) among all anthocyanins identified, the highest content of cyanidin-3-O-galactoside was noted. 
The present study confirmed that drying methods affected the content of anthocyanins; FD and $S D$ resulted in similar retention of anthocyanins. The higher the temperature during VD, the higher the degradation of the anthocyanin content, regardless of the juice formulation.

\subsection{Maillard reaction/caramelisation products}

Previously, 2-furoylmethyl amino acids were identified and quantified in dried commercial products from whole cranberry fruit at levels between 1371 and $6090 \mathrm{mg} / \mathrm{kg}$ protein that corresponded to 0.55 up to $2.44 \mathrm{mg} / 100 \mathrm{~g} \mathrm{dm}$ (Megias-Perez et al., 2014). In the present study, 2-FM-AA were determined for the first time in cranberry juice powders and the quantities found are in agreement with the whole cranberry fruits. The presence of 2-FM-AA might result from its formation during juice pasteurisation process (Soria, Olano, Frias, Penas, \& Villamiel, 2003). The content of 2-FM-AA was approx. 4.8 times higher in products made from sugar-free juice (XAD) than in $15 \% \mathrm{M}$ juice (Table 4). This could be a consequence of the different chemical composition between both formulations. In the XAD extract particular non-polar amino acids might be present (Chul Yang, Shim, Lee \& Moon, 2003). During the drying process, sugars release from glycosides or those that were not completely removed by XAD, could react with those components leading to the formation of 2-furoylmethyl amino acids. Maltodextrin addition to the juice could alter the proportions of amino acids/sugars leading to the lower production of 2-FM-AA. The highest content of FUR was noted using SD process, where the temperature was the highest among all techniques used. Vacuum drying up to $80^{\circ} \mathrm{C}$ caused increase in the content of 2-FM-AA, whereas further increase in the temperature led to a significant degradation. Previously, it was proven that the 2-FM-AA content did not increase linearly with an increase in the temperature during processing, its content decrease after certain point probably leading to the formation of further Maillard intermediates and end products (Erbersdobler \& Somoza, 2007). Similarly to Megías-Pérez et al. (2014) the formation of 2-FMAA was noted also in powders obtained using FD. When influence of the drying process on the formation of 2-FM-AA was considered, comparable observation was made in case of powders obtained by addition of $15 \%$ maltodextrin. In this case, VD at $80{ }^{\circ} \mathrm{C}$ promoted its formation the greater extend. The identification and quantification of 2-FM-AA in cranberry powders obtained from different juice formulation might be a practical tool to prove a heat treatment.

Identification and quantification of 5-hydroxymethylfurfural (HMF), a thermally generated contaminant in foods, is currently more often used as a quality indicator of processed fruit products (Murkovic \& Pichler, 2006)(Capuano \& Fogliano, 2011). The HMF was identified and quantified in all analysed cranberry powders (Table 4), regardless of the juice formulation. Its presence in freeze-dried samples in relatively low quantities could be a result of cranberry juice processing (pasteurisation) before commercialisation. Cranberry powders produced from sugar free juice (XAD) had the content of HMF approx. 4 times higher when compared to powders gained after $15 \% \mathrm{M}$ juice. This could be connected with a relatively high content of chlorogenic acid in those products in comparison to powders obtained from 15\% M juice. Zhang et al. (2016) reported that the presence of this constituent significantly increased the formation of HMF in model systems by promoting the formation of its precursor, 3-deoxosone. In the present study, a high positive correlation between HMF and chlorogenic acid was indicated ( $r=0.9115)$. Among the drying methods applied, the significant impact of temperature on the formation of HMF was indicated. The highest content of this compounds was noted after VD at $100{ }^{\circ} \mathrm{C}$ and SD, regardless of the juice formulation. The increase in the temperature during VD accelerated the formation of HMF almost 4.2- and 1.6 times when compared to freeze drying process of XAD and $15 \% \mathrm{M}$ juice, respectively.

Taking into account the presence of both quality indicators i.e. 2-FM-AA and HMF in cranberry powders, it can be concluded that similarly to Rada-Mendoza, Sanz, Olano and Villamiel (2004) the 2-FM-AA is less sensitive to increase in its content within the temperature during drying than HMF. Clearly, a relatively high content of HMF in the cranberry powders and low values of 2-FM-AA could point out that products were submitted to severe process conditions. 


\subsection{Antioxidant capacity}

The antioxidant capacity of cranberry powders measured by TEAC ABTS, TEAC DPPH and photochemiluminescence (PCL ACW, PCL ACL) assays was significantly higher (up to 40 times) for powers obtained from sugar free juice (XAD) when compared to those gained after addition of maltodextrin (Table 4). The antioxidant capacity of XAD powders determined by TEAC DPPH, PCL ACW and PCL ACL was the highest after spray drying, whereas the highest ability to scavenge ABTS radical cations was noted after freeze-drying process. In case of powders obtained after addition on $15 \%$ maltodextrin, the antioxidant capacity measured by TEAC ABTS was the highest after spray drying, whereas TEAC DPPH and PCL ACW resulted in the highest values after freeze drying process. Generally, the highest ability of products obtained from XAD to scavenge the ABTS ${ }^{*}$ radical cations and $D P P H{ }^{\bullet} \square$ was noted after FD and SD, when compared to VD. The increase in the temperature during VD resulted in lower values of TEAC ABTS and DPPH that connected with degradation of polyphenolic compounds present in the powders ( $r=0.976$ and $r=0.993$, respectively).

The antioxidant capacity of lipid soluble compounds (ACL) was almost 2 times higher when compared to water soluble compounds (ACW) for Aronia powders (Horszwald et al., 2013), Spray drying process caused the highest retention of lipid soluble and water soluble compounds, whereas the greatest degradation was noted after VD at $60{ }^{\circ} \mathrm{C}$ and $80^{\circ} \mathrm{C}$, respectively. Further increase in the temperature resulted in increase in PCL ACW and ACL values suggesting the possible changes in chemical composition indicating the presence or formation of compounds able to scavenge $\mathrm{O}_{2}{ }^{\circ}$.

Thus, the antioxidant capacity of the cranberry powders was more influenced by the juice formulation than by the drying method applied. However, the SD and FD process might be both applied to obtain products with high antioxidant content.

\subsection{Colour}

Cranberry powders might be divided to two groups: (i) dark powders made from sugar-free juice (XAD) and (ii) bright powders obtained from juice with $15 \%$ addition of maltodextrin $(15 \% \mathrm{M})$ in which the average value of coordinate $L^{*}$ was almost 1.5 times higher when compare to first group (Table 5). Similarly to blueberry and strawberry powders (Fegus et al., 2015), the brightest dried products were obtained using SD, regardless of the juice formulation. In case of XAD powders, the highest retention of red pigments $\left(a^{*}\right)$ and the greater yellowness values $\left(b^{*}\right)$ were noted after SD. VD, regardless of the temperature applied, resulted in degradation on average $79 \%$ of red pigments in powders obtained from juice extracts when compared to SD. In the second group consisted of powders obtained from 15\% M juice, the highest value of coordinate $a^{*}$ in was noted after FD process (Table 5). In contrast to XAD powders, the lowest values of coordinate $b^{*}$ in $15 \% \mathrm{M}$ powders were noted after SD suggesting the strong influence of carrier addition on the colour changes that could be used a practical tool in product design. Chroma $\left(C^{*}\right)$ connected with the colour intensity of samples (Pathare, Opara, \& Al-Said, 2012) was significantly higher in powders obtained from the $15 \% \mathrm{M}$ juice. Powders obtained in this way were more intense in red colour than the dark (almost black) powders gained from juice extracts. Among the samples analysed, the highest chroma values was noted for the spray dried powder gained from the cranberry extracts which was connected with the highest value of coordinated $a^{*}$. Hue angle $\left(h^{*}\right)$ defined the difference of a certain colour with a reference to a grey colour with the same lightness (Pathare et al., 2012) and an angle obtained for all the powders analysed represents a red hue. Tracking the changes caused by selected drying methods, $h^{*}$ values were similar between the powders obtained from sugar free extract (XAD). Noticeable alterations in hue angle were indicated in powders obtained from $15 \% \mathrm{M}$ juice with where the lowest values were noted after SD and FD processes. Taking above into 
consideration, cranberry powders might be successfully used as natural food colorants (Camire et al., 2007).

\section{Conclusions}

The production of cranberry powders used for re-solubilisation toward juices or as additives to other food products could be a practical tool for preserving the presence of compounds naturally occurring in cranberries, regardless of the seasonality of the fruits.

Among cranberry powders analysed, the content of total polyphenolic compounds ranged from 589 up to $6435 \mathrm{mg} / \mathrm{kg} \mathrm{dm}$ of powders and was strictly depending of the juice formulation and drying technique used. The highest content of polyphenolic compounds was noted after SD process that might be used as a practical and economical tool for drying. An increase in the temperature during VD of sugar-free cranberry juice resulted in the increase in chlorogenic acid content, even 2.3 times when compared to FD or SD processes. The increase in chlorogenic acids content accelerated the hydroxymethylfurfural formation in the cranberry powders. What is more, an increase in quercetin after VD at $60^{\circ} \mathrm{C}$ was noted, presumably due to quercetin glycoside cleavage. Addition of maltodextrin at the level of $15 \%$ protected the polyphenolic compounds from thermal degradation. In all powders analysed, the presence of 2-furoylmethyl amino acids, as indicators of initial steps of Maillard reaction, has been confirmed. The antioxidant capacity measured by four different methods indicated that spray-drying process could be used as a competitive method to freeze-drying method in the case of cranberry powder production.

\section{Acknowledgement}

The study was funded by the National Science Centre for the post-doctoral internship (FUGA 3) granted to Anna Michalska (Ph.D.) based on decision number DEC-2014/12/S/NZ9/00754.

\section{References}

Aherne, S. A., \& O'Brien, N. M. (2002). Dietary flavonols: chemistry, food content, and metabolism. Nutrition, 18(1), 75-81.

Bhandari, B. R., Senoussi, A., Dumoulin, E. D., \& Lebert, A. (1993). Spray drying of concentrated fruit juices. Drying Technology, 11(5), 1081-1092.

Blumberg, J. B., Camesano, T. A., Cassidy, A., Kris-Etherton, P., Howell, A., Manach, C., ... Vita, J. A. (2013). Cranberries and their bioactive constituents in human health. Advances in Nutrition: An International Review Journal, 4(6), 618-632.

Borges, G., Degeneve, A., Mullen, W., \& Crozier, A. (2010). Identification of flavonoid and phenolic antioxidants in black currants, blueberries, raspberries, red currants, and cranberries. Journal of Agricultural and Food Chemistry, 58(7), 3901-3909.

Borowska, E. J., Mazur, B., Gadzala-Kapciuch, R., \& Buszewski, B. (2009). Polyphenol, anthocyanin and resveratrol mass fractions and antioxidant properties of cranberry cultivars. Food Technology \& Biotechnology, 47(1), 56-61.

Caillet, S., Côté, J., Doyon, G., Sylvain, J.-F., \& Lacroix, M. (2011). Antioxidant and antiradical properties of cranberry juice and extracts. Food Research International, 44(5), 14081413.

Camire, M.E., Dougherty, M.P., Brigs, J.L. (2007). Functionality of fruit powders in extruded corn breakfast cereals. Food Chemistry, 101, 765-770.

Caparino, O. A., Tang, J., Nindo, C. I., Sablani, S. S., Powers, J. R., \& Fellman, J. K. (2012). Effect of drying methods on the physical properties and microstructures of mango (Philippine "Carabao" var.) powder. Journal of Food Engineering, 111(1), 135-148. 
Capuano, E., \& Fogliano, V. (2011). Acrylamide and 5-hydroxymethylfurfural (HMF): A review on metabolism, toxicity, occurrence in food and mitigation strategies. LWT - Food Science and Technology, 44(4), 793-810.

Chen, H., Zuo, Y., \& Deng, Y. (2001). Separation and determination of flavonoids and other phenolic compounds in cranberry juice by high-performance liquid chromatography. Journal of Chromatography A, 913(1-2), 387-395.

Chul Yang, W., Shim, W.G., Lee, J.W., Moon, H. (2003). Adsorption and desorption dynamics od amino acids in a nonionic polymeric sorbent XAD-16 column. Korean Journal of Chemical Engineering, 20, 922-929.

Coimbra, M. A., Nunes, C., Cunha, P. R., \& Guiné, R. (2011). Amino acid profile and Maillard compounds of sun-dried pears. Relation with the reddish brown colour of the dried fruits. European Food Research and Technology, 233(4), 637-646.

Côté, J., Caillet, S., Doyon, G., Dussault, D., Salmieri, S., Lorenzo, G., ... Lacroix, M. (2011). Effects of juice processing on cranberry antioxidant properties. Food Research International, 44(9), 2907-2914.

Côté, J., Caillet, S., Doyon, G., Sylvain, J.-F., \& Lacroix, M. (2010). Analyzing cranberry bioactive compounds. Critical Reviews in Food Science and Nutrition, 50(9), 872-888.

Díaz-García, M. C., Obón, J. M., Castellar, M. R., Collado, J., \& Alacid, M. (2013). Quantification by UHPLC of total individual polyphenols in fruit juices. Food Chemistry, 138(2-3), 938-949.

Erbersdobler, H. F., \& Somoza, V. (2007). Forty years of furosine - Forty years of using Maillard reaction products as indicators of the nutritional quality of foods. Molecular Nutrition \& Food Research, 51(4), 423-430.

Fegus, U., Zigon, U., Peterman, M., \& Zeljko, K. (2015). Effect of drying parameters on physicochemical and sensory properties of fruit powders processed by PGSS-, vacuum- and spray-drying. Acta Chimica Slovenica, (62), 479-487.

Horszwald, A., Andlauer, W., \& Heritier, J. (2013). Characterisation of Aronia powders obtained by different drying processes. Food Chemistry, 5(141), 2858-2863.

Leusink, G. J., Kitts, D. D., Yaghmaee, P., \& Durance, T. (2010). Retention of antioxidant capacity of vacuum microwave dried cranberry. Journal of Food Science, 75(3), 311316.

Megías-Pérez, R., Gamboa-Santos, J., Soria, A. C., Villamiel, M., \& Montilla, A. (2014). Survey of quality indicators in commercial dehydrated fruits. Food Chemistry, 150, 41-48.

Michalska, A., Honke, J., Łysiak, G., \& Andlauer, W. (2016). Effect of drying parameters on the formation of early and intermediate stage products of the Maillard reaction in different plum (Prunus domestica L.) cultivars. LWT - Food Science and Technology, 65, 932938.

Michalska, A., Wojdyło, A., Lech, K., Łysiak, G. P., \& Figiel, A. (2016). Physicochemical properties of whole fruit plum powders obtained using different drying technologies. Food Chemistry, 207, 223-232.

Murkovic, M., \& Pichler, N. (2006). Analysis of 5-hydroxymethylfurfual in coffee, dried fruits and urine. Molecular Nutrition \& Food Research, 50(9), 842-846.

Nicoli, M. C., Anese, M., \& Parpinel, M. (1999). Influence of processing on the antioxidant properties of fruit and vegetables. Trends in Food Science \& Technology, 10(3), 94100.

Oberoi, D. P. S., \& Sogi, D. S. (2015). Effect of drying methods and maltodextrin concentration on pigment content of watermelon juice powder. Journal of Food Engineering, 165, 172-178.

Oszmiański, J., Wojdyło, A., Lachowicz, S., Gorzelany, J., \& Matłok, N. (2016). Comparison of bioactive potential of cranberry fruit and fruit-based products versus leaves. Journal of Functional Foods, 22, 232-242. 
Pappas, E., \& Schaich, K. M. (2009). Phytochemicals of cranberries and cranberry products: characterization, potential health effects, and processing stability. Critical Reviews in Food Science and Nutrition, 49(9), 741-781.

Pathare, P. B., Opara, U. L., \& Al-Said, F. A.-J. (2012). Colour measurement and analysis in fresh and processed foods: a review. Food and Bioprocess Technology, 6(1), 36-60.

Rada-Mendoza, M., Sanz, M. L., Olano, A., \& Villamiel, M. (2004). Formation of hydroxymethylfurfural and furosine during the storage of jams and fruit-based infant foods. Food Chemistry, 85(4), 605-609.

Sanz, M. L., del Castillo, M. D., Corzo, N., \& Olano, A. (2001). Formation of amadori compounds in dehydrated fruits. Journal of Agricultural and Food Chemistry, 49(11), 5228-5231.

Soria, A.C., Olano, A., Frias, J., Penas, E., Villamiel, M. (2003). 2-Furoylmethyl amino acids, hydroxymethylfirfural, carbohydrates and beta-carotene as quality markers of dehydrated carrots. Journal of the Science of Food and Agriculture, 89, 267-273.

Sun, J., Chu, Y.-F., Wu, X., \& Liu, R. H. (2002). Antioxidant and antiproliferative activities of common fruits. Journal of Agricultural and Food Chemistry, 50(25), 7449-7454.

Swaldi, I., Gómez-Caravaca, A. M., Arráez-Román, D., Uberos, J., Lardón, M., SeguraCarretero, A., \& Fernández-Gutiérrez, A. (2012). Characterization by high-performance liquid chromatography with diode-array detection coupled to time-of-flight mass spectrometry of the phenolic fraction in a cranberry syrup used to prevent urinary tract diseases, together with a study of its antibacterial activity. Journal of Pharmaceutical and Biomedical Analysis, 58, 34-41.

Vvedenskaya, I. O., Rosen, R. T., Guido, J. E., Russell, D. J., Mills, K. A., \& Vorsa, N. (2004). Characterization of flavonols in cranberry (Vaccinium macrocarpon) powder. Journal of Agricultural and Food Chemistry, 52(2), 188-195.

White, B. L., Howard, L. R., \& Prior, R. L. (2011). Impact of different stages of juice processing on the anthocyanin, flavonol, and procyanidin contents of cranberries. Journal of Agricultural and Food Chemistry, 59(9), 4692-4698.

Zheng, Z., \& Shetty, K. (2000). Solid-state bioconversion of phenolics from cranberry pomace and role of Lentinus edodes beta-glucosidase. Journal of Agricultural and Food Chemistry, 48(3), 895-900. 


\section{Table 1}

584 Parameters of drying process and water content in cranberry powders (XAD - sugar free juice; $15 \% \mathrm{M}$ - juice with $15 \%$ maltodextrin added).

\begin{tabular}{|c|c|c|c|c|c|}
\hline Process & Equipment & $\begin{array}{l}\text { Process temperature } \\
\left({ }^{\circ} \mathrm{C}\right)\end{array}$ & Sample & $\begin{array}{l}\text { Drying time } \\
\text { (h) }\end{array}$ & $\begin{array}{l}\text { Water content }\left(^{*}\right) \\
(\%)\end{array}$ \\
\hline \multirow[t]{2}{*}{ Freeze drying (FD) } & LSL Secrfroid, Lyolab BII & - 60 (sample); 25 (plate) & XAD & $110 \pm 0.5 \mathrm{~h}$ & $2.5 \pm 0.7 b$ \\
\hline & & & $15 \% M$ & $119 \pm 0.5 i$ & $1.5 \pm 0.2 b$ \\
\hline \multirow[t]{8}{*}{ Vacuum drying (VD) } & Vacuum drying oven, Salvis Lab & 40 & XAD & $38 \pm 0.2 f$ & $1.3 \pm 0.2 b$ \\
\hline & & & $15 \% M$ & $48 \pm 0.4 \mathrm{~g}$ & $1.1 \pm 0.1 \mathrm{~b}$ \\
\hline & & 60 & XAD & $22 \pm 0.2 \mathrm{e}$ & $2.1 \pm 0.6 b$ \\
\hline & & & $15 \% M$ & $22 \pm 0.2 \mathrm{e}$ & $0.3 \pm 0.1 \mathrm{a}$ \\
\hline & & 80 & XAD & $15 \pm 0.1 c$ & $0.7 \pm 0.1 \mathrm{ab}$ \\
\hline & & & $15 \% M$ & $17 \pm 0.1 d$ & $0.2 \pm 0.1 \mathrm{a}$ \\
\hline & & 100 & XAD & $8 \pm 0.2 b$ & $0.4 \pm 0.1 \mathrm{ab}$ \\
\hline & & & $15 \% M$ & $8 \pm 0.2 b$ & $0.4 \pm 0.1 \mathrm{ab}$ \\
\hline \multirow[t]{2}{*}{ Spray drying (SD) } & Mini spray dryer, Buchi & 180 (input), 71 (output) & XAD & $0.5 \pm 0.02 \mathrm{a}$ & $2.4 \pm 0.1 b$ \\
\hline & & & $15 \% M$ & $0.5 \pm 0.02 \mathrm{a}$ & $3.0 \pm 0.8 b$ \\
\hline
\end{tabular}

588

589

590

591

592

593

594

595

596

a,b,c - different letters in the same column $\left({ }^{*}\right)$ represent the statistical different results according to HSD Tukey test $(\mathrm{p}>0.05 ; n=3)$

\section{Table 2}

Polyphenolic compounds identified by LC-MS (QTof) in cranberry powders.

\begin{tabular}{|c|c|c|c|c|}
\hline Compound & $\mathrm{T}_{R}(\mathrm{~min})$ & $\lambda_{\max }(\mathrm{nm})$ & MS & MS/MS \\
\hline \multicolumn{5}{|l|}{ Flavonols } \\
\hline Quercetin-3-O-galacoside & 6.92 & $254 / 352$ & 463.08 & 301.03 \\
\hline Quercetin-3-O-pentoside & 7.36 & $268 / 351$ & 433.07 & 301.03 \\
\hline Quercetin-3-O-rhamnoside & 7.86 & $258 / 349$ & 447.09 & 301.03 \\
\hline Quercetin & 10.01 & $260 / 369$ & 301.03 & \\
\hline Quercetin-benzoyl-galactoside & 10.72 & $258 / 352$ & 567.11 & 301.02 \\
\hline \multicolumn{5}{|l|}{ Phenolic acids } \\
\hline Caffeoyl hexoside & 4.21 & 313 & 341.08 & 179.04 \\
\hline Chlorogenic acid & 4.33 & 324 & 353.08 & $191.01 / 146.05$ \\
\hline$p$-Coumaroyl-hexose isomer & 4.53 & 313 & 325.09 & 163.01 \\
\hline \multicolumn{5}{|l|}{ Flavanols } \\
\hline A-type PA-dimer & 4.66 & 280 & 575.12 & 289.09 \\
\hline A-type PA-dimer & 4.09 & 280 & 575.12 & 289.09 \\
\hline \multicolumn{5}{|l|}{ Anthocyanins } \\
\hline Cyanidin-3-O-galactoside & 4.35 & $278 / 514$ & 449.10 & 287.05 \\
\hline Cyanidin-3-O-arabinoside & 4.84 & $276 / 516$ & 419.09 & 287.05 \\
\hline Peonidin-3-O-galactoside & 5.13 & $279 / 515$ & 463.12 & 301.06 \\
\hline Peonidin-3-O-glucoside & 5.38 & $278 / 520$ & 463.12 & 301.07 \\
\hline Peonidin-3-O-arabinoside & 5.60 & $278 / 519$ & 433.11 & 301.07 \\
\hline
\end{tabular}


603 Table 3

604 The content of polyphenolic compounds present in cranberry powders obtained by different drying techniques $(\mathrm{mg} / \mathrm{kg} \mathrm{dm})(15 \% \mathrm{M}-$ juice with $15 \%$ 605 maltodextrin added; XAD - sugar free juice).

\begin{tabular}{|c|c|c|c|c|c|c|c|c|c|c|c|c|c|c|}
\hline & \multicolumn{7}{|l|}{ Extract (XAD) } & \multicolumn{7}{|l|}{$15 \% \mathrm{M}$} \\
\hline & Freeze drying & VD $40^{\circ} \mathrm{C}$ & VD $60^{\circ} \mathrm{C}$ & VD $80^{\circ} \mathrm{C}$ & VD $100^{\circ} \mathrm{C}$ & Spray drying & $P S D$ & Freeze drying & VD $40^{\circ} \mathrm{C}$ & VD $60^{\circ} \mathrm{C}$ & VD $80^{\circ} \mathrm{C}$ & VD $100^{\circ} \mathrm{C}$ & Spray drying & $P S D^{\circ}$ \\
\hline \multicolumn{15}{|c|}{ Flavonols } \\
\hline Quercetin-3-O-galactoside & $1771 \pm 9 d$ & $1484 \pm 9 c$ & $710 \pm 83 b$ & $201 \pm 22 a$ & $62.3 \pm 3.6 \mathrm{a}$ & $1703 \pm 146 \mathrm{~cd}$ & 89.7 & $276 \pm 10 a$ & $232 \pm 33 a$ & $234 \pm 0.3 a$ & $218 \pm 38 a$ & $175 \pm 21 a$ & $237 \pm 5 a$ & 22.6 \\
\hline Quercetin-3-O-pentoside & $190 \pm 2 d$ & $150 \pm 13 \mathrm{c}$ & $61.9 \pm 8.0 \mathrm{~d}$ & $16.3 \pm 5.2 a$ & $7.5 \pm 1.5 \mathrm{a}$ & $187 \pm 17 d$ & 9.6 & $31.5 \pm 0.1 \mathrm{a}$ & $26.7 \pm 3.1 \mathrm{a}$ & $25.8 \pm 1.7 a$ & $25.3 \pm 4.2 a$ & $19.7 \pm 3.2 \mathrm{a}$ & $27.5 \pm 0.1 \mathrm{a}$ & 2.6 \\
\hline Quercetin-3-O-rhamnoside & $237 \pm 4 c$ & $205 \pm 20 \mathrm{c}$ & $108 \pm 12 b$ & $32.2 \pm 2.8 \mathrm{a}$ & $12.1 \pm 1.0 \mathrm{a}$ & $230 \pm 19 \mathrm{c}$ & 12.4 & $34.5 \pm 1.1 \mathrm{a}$ & $28.8 \pm 4.2 a$ & $26.0 \pm 4.7 \mathrm{a}$ & $27.8 \pm 4.3 \mathrm{a}$ & $23.2 \pm 1.9 a$ & $29.9 \pm 0.3 \mathrm{a}$ & 3.3 \\
\hline Quercetin & $1342 \pm 17 b$ & $1699 \pm 135 b c$ & $2128 \pm 247 c$ & $1718 \pm 329 b c$ & $1426 \pm 135 b$ & $1502 \pm 191 b$ & 216 & $205 \pm 26 a$ & $172 \pm 10 \mathrm{a}$ & $177 \pm 6 a$ & $180 \pm 11 a$ & $146.6 \pm 4.8 \mathrm{a}$ & $132 \pm 2 a$ & 12.8 \\
\hline Quercetin-benzoyl-galactoside & $96 \pm 1 b c$ & $112 \pm 12 \mathrm{c}$ & $128 \pm 14 \mathrm{c}$ & $101 \pm 9 \mathrm{c}$ & $85.4 \pm 7.6 \mathrm{~b}$ & $105 \pm 11 \mathrm{c}$ & 12.7 & $13.1 \pm 0.7 \mathrm{a}$ & $10.9 \pm 1.1 \mathrm{a}$ & $11.2 \pm 0.9 a$ & $11.6 \pm 0.8 \mathrm{a}$ & $9.5 \pm 0.3 \mathrm{a}$ & $8.9 \pm 0.3 a$ & 0.8 \\
\hline \multicolumn{15}{|c|}{ Phenolic acids } \\
\hline Caffeoyl-hexoside & $385 \pm 4 c$ & $347 \pm 23 c$ & $257 \pm 22 b$ & $118 \pm 11 a$ & $74.6 \pm 3.6 \mathrm{a}$ & $367 \pm 28 c$ & 17.9 & $47.1 \pm 1.1 \mathrm{a}$ & $39.9 \pm 5.3 \mathrm{a}$ & $36.4 \pm 4.1 \mathrm{a}$ & $36.6 \pm 2.2 a$ & $34.2 \pm 2.71 \mathrm{a}$ & $41.8 \pm 0.1 \mathrm{a}$ & 3.1 \\
\hline Chlorogenic acid & $125 \pm 0.1 b$ & $143 \pm 8 b$ & $203 \pm 12 c$ & $251 \pm 23 d$ & $277 \pm 12 d$ & $118 \pm 8 b$ & 12.7 & $14.5 \pm 1.6 \mathrm{a}$ & $8.1 \pm 1.1 \mathrm{a}$ & $7.8 \pm 0.9 a$ & $8.4 \pm 0.1 \mathrm{a}$ & $8.4 \pm 0.6 \mathrm{a}$ & $8.1 \pm 0.1 \mathrm{a}$ & 0.9 \\
\hline p-coumaroyl-hexose isomer & $908 \pm 6 c$ & $679 \pm 35 c$ & $247.8 \pm 25.9 b$ & $70 \pm 0.3 \mathrm{ab}$ & $19.2 \pm 0.1 \mathrm{a}$ & $871 \pm 65 c$ & 32.1 & $136 \pm 24 a b$ & $132 \pm 16 \mathrm{ab}$ & $128.5 \pm 3.8 \mathrm{ab}$ & $103 \pm 4 a b$ & $97.5 \pm 14.9 \mathrm{ab}$ & $140 \pm 0.2 a b$ & 13.5 \\
\hline \multicolumn{15}{|c|}{ Flavanols } \\
\hline Procyanidin A' (dimer) & $653 \pm 9 e$ & $452 \pm 14 d$ & $258 \pm 33 c$ & $104 \pm 9 b$ & $54.5 \pm 0.9 \mathrm{ab}$ & $655 \pm 14 \mathrm{e}$ & 16.6 & $87.4 \pm 15.9 \mathrm{~b}$ & $63.5 \pm 1.7 \mathrm{ab}$ & $57.1 \pm 1.8 \mathrm{ab}$ & $54.3 \pm 7.2 \mathrm{ab}$ & $30.6 \pm 3.2 a$ & $83.6 \pm 0.1 \mathrm{~b}$ & 7.3 \\
\hline Procyanidin A" (dimer) & $240 \pm 26 c$ & $236 \pm 40 c$ & $211 \pm 17 c$ & $104 \pm 12 b$ & $47.3 \pm 3.6 a b$ & $271 \pm 1 d$ & 14.7 & $50.3 \pm 6.9 \mathrm{ab}$ & $38.5 \pm 4.8 \mathrm{a}$ & $29.9 \pm 7.2 a$ & $33.8 \pm 7.4 a$ & $28.6 \pm 6.1 \mathrm{a}$ & $41.6 \pm 0.1 \mathrm{a}$ & 6 \\
\hline \multicolumn{15}{|c|}{ Anthocyanins } \\
\hline Cyanidin-3-O-galactoside & $272 \pm 1 e$ & $238 \pm 25 \mathrm{de}$ & $197 \pm 24 d$ & $116 \pm 15 c$ & $77.8 \pm 3.3 \mathrm{bc}$ & $242 \pm 21 \mathrm{de}$ & 17.8 & $38.2 \pm 0.6 \mathrm{ab}$ & $31.2 \pm 2.7 \mathrm{ab}$ & $28.9 \pm 2.2 \mathrm{ab}$ & $15.7 \pm 3.5 \mathrm{ab}$ & $9.5 \pm 1.2 \mathrm{a}$ & $32.8 \pm 1.2 a b$ & 2.2 \\
\hline Cyanidin-3-O-arabinoside & $173 \pm 1 e$ & $153 \pm 17 \mathrm{de}$ & $125 \pm 15 d$ & $64.9 \pm 8.7 \mathrm{c}$ & $39.3 \pm 1.2 \mathrm{bc}$ & $155 \pm 14 \mathrm{de}$ & 11.3 & $23.3 \pm 0.5 \mathrm{~b}$ & $18.9 \pm 1.1 \mathrm{ab}$ & $20.6 \pm 2.9 \mathrm{ab}$ & $19.2 \pm 0.3 \mathrm{ab}$ & $4.9 \pm 1.0 \mathrm{a}$ & $20.3 \pm 0.6 \mathrm{ab}$ & 1.4 \\
\hline Peonidin-3-O-galactoside & $21.2 \pm 0.1 \mathrm{e}$ & $18.9 \pm 2.1 \mathrm{de}$ & $16.0 \pm 2.1 \mathrm{~d}$ & $9.8 \pm 1.4 \mathrm{c}$ & $6.8 \pm 0.3 b c$ & $19.0 \pm 1.6 \mathrm{de}$ & 1.5 & $2.9 \pm 0.1 \mathrm{ab}$ & $2.4 \pm 0.2 \mathrm{a}$ & $2.7 \pm 0.4 a b$ & $2.5 \pm 0.0 \mathrm{a}$ & $0.9 \pm 0.1 \mathrm{a}$ & $2.6 \pm 0.1 \mathrm{ab}$ & 0.2 \\
\hline Peonidin-3-O-glucoside & $2.3 \pm 0.1 \mathrm{~d}$ & $1.9 \pm 0.2 \mathrm{~cd}$ & $1.75 \pm 0.21 \mathrm{c}$ & $1.15 \pm 0.14 b$ & $0.84 \pm 0.03 b$ & $1.96 \pm 0.18 \mathrm{~cd}$ & 0.16 & $0.32 \pm 0.01 \mathrm{a}$ & $0.25 \pm 0.02 a$ & $0.23 \pm 0.02 a$ & $0.22 \pm 0.05 a$ & $0.15 \pm 0.04 a$ & $0.25 \pm 0.01 \mathrm{a}$ & 0.03 \\
\hline Peonidin-3-O-arabinoside & $7.6 \pm 0.1 \mathrm{~d}$ & $6.7 \pm 0.8 \mathrm{~cd}$ & $5.46 \pm 0.69 \mathrm{c}$ & $2.68 \pm 0.36 \mathrm{~b}$ & $1.62 \pm 0.06 \mathrm{ab}$ & $6.79 \pm 0.58 \mathrm{~cd}$ & 0.51 & $1.02 \pm 0.02 a$ & $0.82 \pm 0.04 a$ & $0.77 \pm 0.04 \mathrm{a}$ & $0.45 \pm 0.05 \mathrm{a}$ & $0.28 \pm 0.03 a$ & $0.87 \pm 0.03 a$ & 0.03 \\
\hline
\end{tabular}

608 a,b,c - different letters in the same row indicated a significant difference $(p>0.05 ; n=3) ;{ }^{*} P S D-$ pooled standard deviation 


\section{Table 4}

The content of 2-furoylmethyl amino acids (2-FM-AA) and hydroxymethylfurfural (HMF) and antioxidant capacity (TEAC ABTS, TEAC DPPH, photochemiluminescence PCL) of cranberry powders (average \pm SD,$n=3)(15 \% \mathrm{M}$ - juice with $15 \%$ maltodextrin added; XAD - sugar free juice).

\begin{tabular}{|c|c|c|c|c|c|c|}
\hline \multirow{2}{*}{ Sample } & \multirow{2}{*}{ Process } & \multicolumn{2}{|c|}{ Maillard reaction/caramelisation products } & \multicolumn{3}{|c|}{ Antioxidant capacity } \\
\hline & & $\begin{array}{l}\text { 2-FM-AA } \\
(\mathrm{mg} / 100 \mathrm{~g} \mathrm{dm})\end{array}$ & $\begin{array}{l}\mathrm{HMF} \\
(\mathrm{mg} / \mathrm{kg} \mathrm{dm})\end{array}$ & $\begin{array}{l}\text { TEAC ABTS } \\
(\mathrm{mmol} \text { Trolox/100 }\end{array}$ & $\begin{array}{l}\text { TEAC DPPH } \\
\mathrm{dm})\end{array}$ & PCL ACW \\
\hline \multirow[t]{6}{*}{ XAD } & Freeze drying & $1.70 \pm 0.18 b$ & $70.3 \pm 0.6 \mathrm{a}$ & $188.83 \pm 3.57 \mathrm{i}$ & $201.41 \pm 5.34 \mathrm{e}$ & $98.92 \pm 0.16 \mathrm{de}$ \\
\hline & VD $40^{\circ} \mathrm{C}$ & $2.01 \pm 0.32 c$ & $118.3 \pm 4.2 b$ & $169.05 \pm 6.97 \mathrm{~h}$ & $191.19 \pm 2.19 \mathrm{~d}$ & $89.38 \pm 2.95 \mathrm{~cd}$ \\
\hline & VD $60^{\circ} \mathrm{C}$ & $2.29 \pm 0.41 c$ & $167.6 \pm 6.7 \mathrm{c}$ & $155.55 \pm 2.81 \mathrm{~g}$ & $134.75 \pm 3.12 \mathrm{c}$ & $88.36 \pm 0.04 c$ \\
\hline & VD $80^{\circ} \mathrm{C}$ & $2.48 \pm 0.39 c$ & $199.4 \pm 0.5 d$ & $117.25 \pm 5.53 f$ & $48.39 \pm 2.35 b$ & $83.49 \pm 2.94 c$ \\
\hline & VD $100^{\circ} \mathrm{C}$ & $0.87 \pm 0.06 \mathrm{a}$ & $293.1 \pm 2.9 \mathrm{e}$ & $71.86 \pm 2.19 \mathrm{e}$ & $44.56 \pm 2.10 \mathrm{~b}$ & $88.04 \pm 1.00 \mathrm{c}$ \\
\hline & Spray drying & $2.86 \pm 0.51 \mathrm{c}$ & $198.1 \pm 5.4 \mathrm{~d}$ & $167.59 \pm 5.17 \mathrm{~h}$ & $203.80 \pm 4.01 \mathrm{e}$ & $102.45 \pm 4.28 f$ \\
\hline$P S D^{*}$ & & 0.28 & 5.85 & 4.57 & 3.41 & 3.03 \\
\hline \multirow[t]{6}{*}{$15 \% M$} & Freeze drying & $0.12 \pm 0.02 \mathrm{a}$ & $34.5 \pm 1.7 \mathrm{a}$ & $4.65 \pm 0.23 c$ & $6.43 \pm 0.30 \mathrm{a}$ & $4.23 \pm 0.16 b$ \\
\hline & VD $40^{\circ} \mathrm{C}$ & $0.14 \pm 0.02 \mathrm{a}$ & $35.1 \pm 0.6 \mathrm{a}$ & $3.45 \pm 0.04 b$ & $6.04 \pm 0.20 \mathrm{a}$ & $4.13 \pm 0.08 b$ \\
\hline & VD $60^{\circ} \mathrm{C}$ & $0.26 \pm 0.05 b$ & $39.1 \pm 3.4 b$ & $1.21 \pm 0.05 a$ & $4.11 \pm 0.18 a$ & $3.94 \pm 0.04 a b$ \\
\hline & VD $80^{\circ} \mathrm{C}$ & $0.91 \pm 0.04 \mathrm{c}$ & $44.1 \pm 2.5 \mathrm{c}$ & $3.11 \pm 0.08 b$ & $3.76 \pm 0.07 a$ & $3.73 \pm 0.07 a$ \\
\hline & VD $100^{\circ} \mathrm{C}$ & $0.71 \pm 0.05 d$ & $57.1 \pm 2.4 \mathrm{e}$ & $5.15 \pm 0.22 d$ & $3.65 \pm 0.16 a$ & $3.99 \pm 0.02 a b$ \\
\hline & Spray drying & $0.35 \pm 0.01 b$ & $46.8 \pm 1.6 \mathrm{~d}$ & $4.81 \pm 0.20 \mathrm{~cd}$ & $3.12 \pm 0.16 \mathrm{a}$ & $4.22 \pm 0.03 b$ \\
\hline$P S D^{*}$ & & 0.04 & 5.75 & 0.15 & 0.19 & 0.10 \\
\hline
\end{tabular}

a,b,c - different letters in the same column indicated a significant difference $(p>0.05 ; n=3)$; ${ }^{*}$ PSD - pooled standard deviation

\section{Table 5}

Colour of cranberry powders obtained by selected drying methods (15\% M - juice with $15 \%$ maltodextrin added; XAD - sugar free juice).

\begin{tabular}{|c|c|c|c|c|c|c|}
\hline \multirow{2}{*}{ Sample } & \multirow{2}{*}{ Method } & \multicolumn{4}{|l|}{ Colour } & \multirow{2}{*}{ Hue angle $\left({ }^{\circ}\right)$} \\
\hline & & $L^{*}$ & $a^{*}$ & $b^{*}$ & Chroma $\left(C^{*}\right)$ & \\
\hline \multirow[t]{6}{*}{ XAD } & Freeze drying & $38.6 \pm 0.6 \mathrm{c}$ & $23.7 \pm 0.4 c$ & $5.0 \pm 0.0 c$ & $24.3 \pm 0.4 c$ & $12.1 \pm 0.1 b c$ \\
\hline & VD $40^{\circ} \mathrm{C}$ & $35.2 \pm 0.1 \mathrm{ab}$ & $12.1 \pm 0.4 b$ & $2.5 \pm 0.1 b$ & $12.2 \pm 0.4 b$ & $11.8 \pm 0.3 b c$ \\
\hline & VD $60^{\circ} \mathrm{C}$ & $34.0 \pm 0.4 \mathrm{a}$ & $4.1 \pm 0.2 \mathrm{a}$ & $0.8 \pm 0.0 a$ & $4.1 \pm 0.2 \mathrm{a}$ & $11.5 \pm 0.8 b$ \\
\hline & VD $80^{\circ} \mathrm{C}$ & $35.4 \pm 0.2 a b$ & $5.5 \pm 0.3 a$ & $1.1 \pm 0.1 \mathrm{a}$ & $5.6 \pm 0.3 a$ & $12.0 \pm 0.4 b c$ \\
\hline & VD $100^{\circ} \mathrm{C}$ & $36.7 \pm 0.1 \mathrm{bc}$ & $9.6 \pm 0.2 b$ & $2.0 \pm 0.0 \mathrm{~b}$ & $9.8 \pm 0.2 b$ & $12.1 \pm 0.1 \mathrm{bc}$ \\
\hline & Spray drying & $45.4 \pm 0.1 d$ & $36.7 \pm 0.3 \mathrm{~g}$ & $8.1 \pm 0.2$ ef & $37.6 \pm 0.4 \mathrm{~g}$ & $12.4 \pm 0.2 \mathrm{c}$ \\
\hline \multirow[t]{4}{*}{$15 \% \mathrm{M}$} & Freeze drying & $59.1 \pm 0.5 \mathrm{~g}$ & $34.7 \pm 0.2 \mathrm{fg}$ & $6.1 \pm 0.1 d$ & $35.3 \pm 0.2 \mathrm{fg}$ & $10.0 \pm 0.2 \mathrm{a}$ \\
\hline & VD $40^{\circ} \mathrm{C}$ & $49.8 \pm 1.4 \mathrm{e}$ & $31.3 \pm 0.9 \mathrm{e}$ & $7.5 \pm 0.1 \mathrm{e}$ & $32.2 \pm 0.9 \mathrm{e}$ & $13.5 \pm 0.3 d$ \\
\hline & VD $60^{\circ} \mathrm{C}$ & $46.8 \pm 1.9 \mathrm{~d}$ & $28.1 \pm 4.1 \mathrm{~d}$ & $7.2 \pm 1.2 \mathrm{e}$ & $29.1 \pm 4.3 d$ & $14.4 \pm 0.4 \mathrm{e}$ \\
\hline & VD $80^{\circ} \mathrm{C}$ & $51.1 \pm 0.5 \mathrm{e}$ & $27.9 \pm 0.5 d$ & $8.5 \pm 0.1 \mathrm{fg}$ & $29.1 \pm 0.5 d$ & $16.9 \pm 0.0 f$ \\
\hline
\end{tabular}




\begin{tabular}{llllll}
$\operatorname{VD} 100{ }^{\circ} \mathrm{C}$ & $55.8 \pm 1.2 \mathrm{f}$ & $33.6 \pm 0.7 \mathrm{ef}$ & $9.1 \pm 0.2 \mathrm{~g}$ & $34.8 \pm 0.7 \mathrm{efg}$ & $15.1 \pm 0.3 \mathrm{e}$ \\
Spray drying & $71.6 \pm 0.2 \mathrm{~h}$ & $31.9 \pm 0.1 \mathrm{e}$ & $5.5 \pm 0.1 \mathrm{~cd}$ & $32.4 \pm 0.1 \mathrm{ef}$ & $9.7 \pm 0.1 \mathrm{a}$ \\
\hline
\end{tabular}

627 a,b,c - different letters in the same column indicated a significant difference $(p>0.05 ; n=3)$

628 